\title{
Alloy oxide equilibria in the Cr-Mn-O system
}

\author{
S RANGANATHAN and J P HAJRA \\ Department of Metallurgy, Indian Institute of Science, Bangalore 560012 , India \\ MS received 17 March 1987
}

\begin{abstract}
The phase boundaries of the $\mathrm{Cr}-\mathrm{Mn}-\mathrm{O}$ system have been investigated by alloyoxide equilibria at 1173 and $1273 \mathrm{~K}$ and by isopiestic technique at $1323 \mathrm{~K}$. The oxide phases which coexist in equilibrium with the $\mathrm{Cr}-\mathrm{Mn}$ alloys are determined by $\mathrm{x}$-ray diffraction studies. The results of the experiments indicate the presence of $\mathrm{MnO}$ in equilibrium with $\mathrm{Mn}$-rich alloy whereas $\mathrm{MnCr}_{2} \mathrm{O}_{4}$ and $\mathrm{Cr}_{2} \mathrm{O}_{3}$ phases coexist with almost pure $\mathrm{Cr}$. A threephase equilibrium consisting of $\mathrm{MnCr}_{2} \mathrm{O}_{4}$ and $\mathrm{MnO}$ phases has been detected at the alloy composition $\mathrm{X}_{\mathrm{Mn}}=0.252$ at $1323 \mathrm{~K}$. The composition of the alloy delineates the phase boundaries in the isothermal sections of the system. The results are interpreted by thermodynamic analysis of the $\mathrm{Cr}-\mathrm{Mn}-\mathrm{O}$ system using the data from the isopiestic measurements and those available in the literature.
\end{abstract}

Keywords. Cr-Mn-O; alloy oxide equilibria; isopiestic technique.

\section{Introduction}

Chromium and manganese are important components of high temperature alloys. Alloys containing the elements undergo oxidation with the formation of spinel phases during high temperature applications. Information regarding the various types of phases which exist in the $\mathrm{Cr}-\mathrm{Mn}-\mathrm{O}$ system, the stability and proportions of the phases as a function of composition and temperature is important in assessing the applicability of the alloys as high temperature materials. An understanding of the stability of these phases is also important in various thermodynamic studies involving solid state galvanic cells. No studies on thermodynamics and phase equilibria in the system have so far been reported in the literature. Investigations have been carried out to identify various oxide phases and delineate the phase boundaries in the $\mathrm{Cr}-\mathrm{Mn}-\mathrm{O}$ system in equilibrium with $\mathrm{Cr}-\mathrm{Mn}$ alloys as a function of alloy composition and temperature. The equilibrium phases have been detected by $\mathrm{x}$ ray diffraction studies and the results obtained in the experiments have been interpreted by thermodynamic analysis of the system.

\section{Experimental aspects}

\subsection{Materials and preparation}

The metals, chromium and manganese were $99.99 \%$ pure and supplied by Johnson and Matthey Chemicals, UK and Alfa Products of Thiokal Corporation, USA, respectively. The alloys were prepared by melting weighed quantities of the metals in a recrystallized alumina crucible using a high frequency generator under an atmosphere of pure argon. The gas was purified by passing it over calcium granules heated to $873 \mathrm{~K}$. The alloys were analysed using a Shimadzu spectrophotometer 
(UV-visible) after oxidizing a solution containing the alloy to a mixture of permanganate and dichromate as described by Vogel (1969).

Manganese oxide was prepared by reducing $\mathrm{Mn}_{2} \mathrm{O}_{3}$ in a stream of hydrogen at $1273 \mathrm{~K}$. Manganese chromate was prepared by heating a mixture of potassium manganese chloride, $\mathrm{K}_{2} \mathrm{MnCl}_{4}$ and lithium chromium oxide, $\mathrm{LiCrO}_{2}$ at $873 \mathrm{~K}$ in an atmosphere of pure nitrogen which was dried by passing it over phosphorus pentoxide as described by Busch (1980). Chromium oxide, $\mathrm{Cr}_{2} \mathrm{O}_{3}$, was prepared by decomposition of chromium carbonate at $1073 \mathrm{~K}$ in air. The oxides obtained were then confirmed using an x-ray diffractograph by comparing with $d$-spacing data available in the literature.

\section{Apparatus and procedure}

A mixture of an alloy of given composition and a small amount of oxide was repeatedly mixed and ground in an agate mortar to ensure intimate contact between the reactant phases. The alloy-oxide system was heterogenous in nature and fine grinding followed by mixing prior to pelletization was required to enhance the slow solid state diffusion process. The alloy + oxide mixture was pelletized using a steel die to a pellet of about $7 \mathrm{~mm}$ dia. The pellet was then enclosed in an outer pellet of $\mathrm{MnO}$ as shown in figure 1. Manganese, being a volatile component in the alloys at the temperatures under investigation, the outer pellet of $\mathrm{MnO}$ restricts the loss of $\mathrm{Mn}$ due to vaporization. The pellet was then introduced in a quartz capsule which was evacuated and filled with argon. It was then re-evacuated and sealed. The quartz capsule was placed carefully in the even temperature zone of a furnace for $720 \mathrm{hr}$. The furnace zone was controlled within $\pm 1 \mathrm{~K}$. The time required for the alloy + oxide system to reach equilibrium was determined by several trial runs. At the end of this period, the quartz capsule was quenched in water and the alloy toxide pellet inside the outer $\mathrm{MnO}$ pellet was recovered carefully. An x-ray diffractograph of pellet was then taken after grinding and polishing the surface, to identify the oxide phase present in equilibrium with the alloy at the experimental temperature. Grinding of the alloy + oxide pellet is necessary to avoid any $\mathrm{MnO}$ particles adhering to the surface. The equilibrium experiments were carried out at 1173 and $1273 \mathrm{~K}$. Since the alloy phase cannot be separately analysed due to fineness of the grinding and intimate mixing of the reactants, a small quantity of the oxide phase was used to ensure insignificant compositional changes during the experiments. Each alloy composition had been repeated with starting oxide phase as either $\mathrm{MnO}$ or $\mathrm{MnCr}_{2} \mathrm{O}_{4}$ separately irrespective of the resultant equilibrium phase as shown in table 1 . These repeat experiments were required to ascertain the composition of the alloys in equilibrium with the oxide phases. No side reaction between $\mathrm{MnO}$ in the alloy + oxide pellet and quartz was detected by $x$-ray diffraction studies.

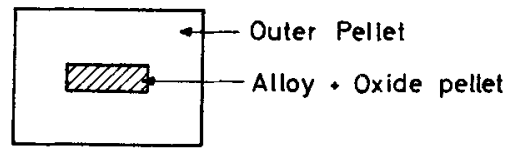

Figure 1. Schematic sketch of an alloy + oxide pellet inserted in a pellet of $\mathrm{MnO}$ used in the alloy-oxide equilibrium experiments. 
Table 1. Results of the alloy oxide equilibria at $1173 \mathrm{~K}$ and $1273 \mathrm{~K}$.

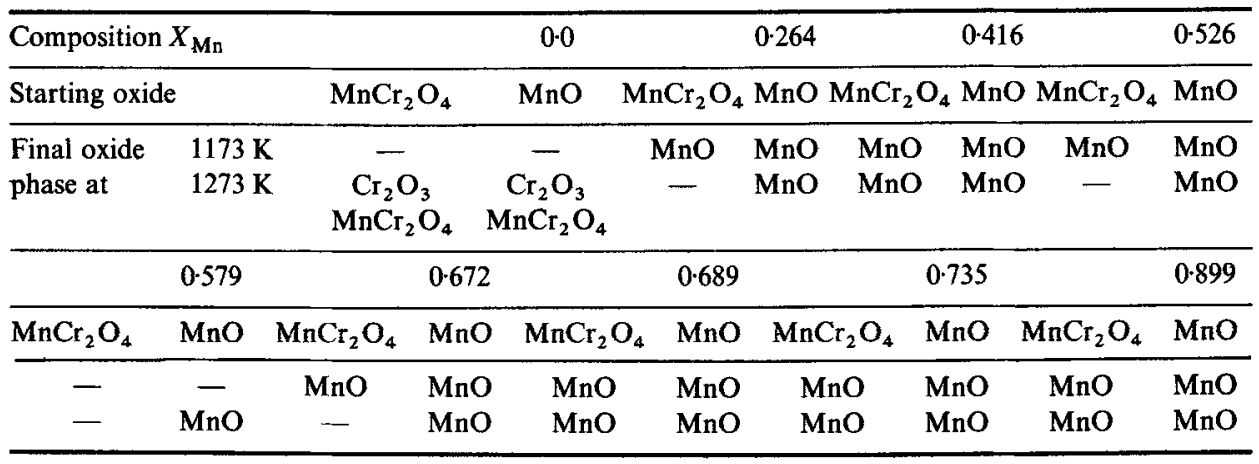

\section{Isopiestic experiments}

A number of alloys were used in the isopiestic experiments in order to establish the compositions of the alloys and the corresponding oxide phases in equilibrium at $1323 \mathrm{~K}$. In these experiments, two alloy pellets of different compositions and an alloy pellet mixed with a small quantity of $\mathrm{Cr}_{2} \mathrm{O}_{3}$ were taken in the upper part of a quartz capsule as shown in figure 2 . The lower part of the capsule contained a pellet of pure $\mathrm{Mn}$. A chromel-alumel thermocouple attached close to it measured the temperature of the pellet. The capsule was then held vertically in a furnace such that the upper part containing the alloy pellets was in the even temperature zone of the furnace. An

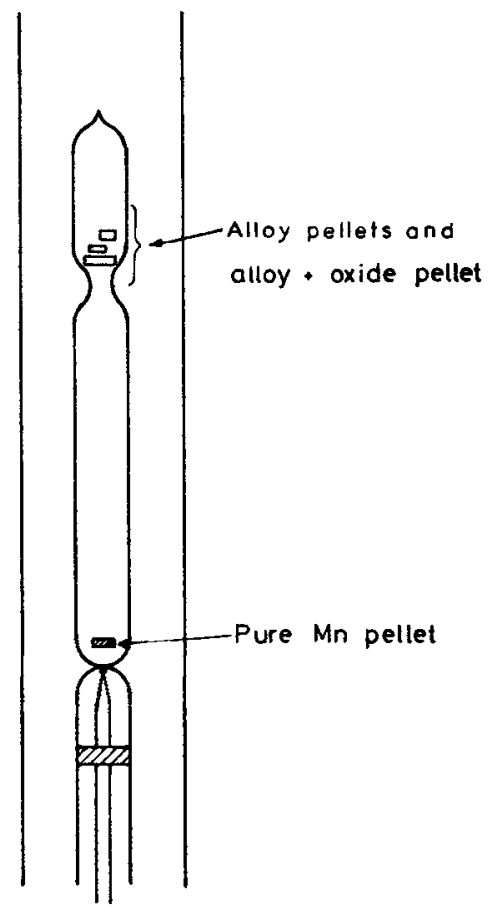

Figure 2. Schematic sketch depicting the experimental set-up for the isopiestic technique. 
additional chromel-alumel thermocouple placed in the zone measured the temperature of the alloy sample. The temperature of the Mn pellet dictated the partial pressure of $\mathrm{Mn}$ in the capsule. The system was considered to be in equilibrium as the composition of the alloys placed in the upper part of the capsule approached that of an equilibrium value. The temperature distribution in the furnace was such that the manganese pellet was at a lower temperature than that of the alloy pellets. After the equilibrium which required $500 \mathrm{hr}$, the capsule was quenched in air. The compositions of the alloy pellets were then determined by chemical analysis using a spectrophotometer as already described. The alloy + oxide pellet was then subjected to $\mathrm{x}$-ray analysis to determine the oxide phase present as shown in table 2. Since two alloy pellets reached the same composition starting from different initial compositions, the composition of the alloy in the alloy + oxide pellet was considered to be the same as that of the other alloy pellets. The initial composition of the alloy in the alloy + oxide pellet was chosen fairly close to those of the other two so that the same equilibrium value could be achieved in the samples. An added advantage of the method is that, apart from the alloy + oxide equilibrium studies, thermodynamics of the Cr-Mn system could also be determined simultaneously. One set of experimental results is reported in table 2 . This constitutes a part of a major programme on the determination of thermodynamic properties of Mn-based systems, the details of which are to be published elsewhere.

\section{Results and discussion}

The tie line compositions of $\mathrm{Cr}-\mathrm{Mn}$ alloys in equilibrium with the corresponding oxide phases at 1173 and $1273 \mathrm{~K}$ are summarized in table 1 and those at $1323 \mathrm{~K}$ in table 2. These data indicate that for alloys $X_{\mathrm{Cr}} \simeq 1 \cdot 0$, the stable oxide phases are $\mathrm{Cr}_{2} \mathrm{O}_{3}$ and $\mathrm{MnCr}_{2} \mathrm{O}_{4}$ irrespective of the starting oxide phase used in the equilibrium experiments. However, as the $\mathrm{Mn}$ content of the alloy is increased close to $X_{\mathrm{Mn}}=0 \cdot 252, \mathrm{MnCr}_{2} \mathrm{O}_{4}$ is recognized to be the only oxide phase in equilibrium as determined by the isopiestic technique at $1323 \mathrm{~K}$. The alloy-oxide system exhibits

Table 2. Results of isopiestic experiments at temperature $1323 \mathrm{~K}$ Starting oxide phase (in all cases): $\mathrm{Cr}_{2} \mathrm{O}_{3}$.

\begin{tabular}{ll}
\hline Composition $X_{\mathrm{Mn}}$ & Final oxide phases \\
\hline 0.04 & $\mathrm{MnCr}_{2} \mathrm{O}_{4}$ \\
& $\mathrm{Cr}_{2} \mathrm{O}_{3}$ \\
0.067 & $\mathrm{MnCr}_{2} \mathrm{O}_{4}$ \\
0.152 & $\mathrm{MnCr}_{2} \mathrm{O}_{4}$ \\
0.188 & $\mathrm{MnCr}_{2} \mathrm{O}_{4}$ \\
0.215 & $\mathrm{MnCr}_{2} \mathrm{O}_{4}$ \\
0.233 & $\mathrm{MnCr}_{2} \mathrm{O}_{4}$ \\
0.252 & $\mathrm{MnO}$ \\
0.337 & $\mathrm{MnCr}_{2} \mathrm{O}_{4}$ \\
0.392 & $\mathrm{MnO}$ \\
0.570 & $\mathrm{MnO}$ \\
0.586 & $\mathrm{MnO}$ \\
\hline
\end{tabular}


similar trends as $X_{\mathrm{Mn}}$ tends to 0.252 independent of the starting oxide phase used in the experiments. However, the change-over of the type of oxide phase from $\mathrm{MnCr}_{2} \mathrm{O}_{4}$ to $\mathrm{MnO}$ occurs when $X_{\mathrm{Mn}}=0.252$ as shown in tables 1 and 2 . The change-over composition is considered to be an important feature which essentially determines the existence of the three-phase equilibrium in the $\mathrm{Cr}-\mathrm{Mn}-\mathrm{O}$ system. Tables 1 and 2 further indicate the existence of a $\mathrm{MnO}$ phase in equilibrium with the alloys as $\mathrm{X}_{\mathrm{Mn}}$ is increased beyond the change-over composition. These compositions roughly demarcate the phase boundaries in the $\mathrm{Cr}-\mathrm{Mn}-\mathrm{O}$ system in terms of the type of oxide phase which coexist in equilibrium with the Cr-Mn alloys as a function of alloy composition and temperature. The results summarized in tables 1 and 2 have been interpreted by thermodynamic calculation in the subsequent section.

\section{Thermodynamic analysis}

The determination of the isothermal sections of the Cr-Mn-O system is based on equilibrium calculation and information from the constituent binaries. Various alloy phases and their phase boundaries in the $\mathrm{Cr}-\mathrm{Mn}$ system as a function of composition and temperature were recently computed by Venkataraman and Neuman (1986). These phase designations and boundaries are adopted in the present study. The composition of the alloy in equilibrium with the oxide phases has been determined from thermodynamic properties of the $\mathrm{Cr}-\mathrm{Mn}$ alloys and equilibrium constants of the following reactions:

$$
\begin{aligned}
& \mathrm{Mn}=\frac{1}{2} \mathrm{O}_{2}(\mathrm{~g})=\mathrm{MnO}(\mathrm{s}), \\
& 2 \mathrm{Cr}+\frac{3}{2} \mathrm{O}_{2}(\mathrm{~g})=\mathrm{Cr}_{2} \mathrm{O}_{3}(\mathrm{~s}), \\
& \mathrm{Mn}+2 \mathrm{Cr}+2 \mathrm{O}_{2}(\mathrm{~g})=\mathrm{MnCr}_{2} \mathrm{O}_{4} .
\end{aligned}
$$

The equilibrium constants of (1), (2) and (3) at 1173, 1273 and $1323 \mathrm{~K}$ are obtained from the standard free energy of formation of $\mathrm{MnO}$ and $\mathrm{MnCr}_{2} \mathrm{O}_{4}$ respectively. The standard free energy of formation of $\mathrm{MnO}$ is obtained from Barin and Knacke (1973) and Barin et al (1977) and those of $\mathrm{Cr}_{2} \mathrm{O}_{3}$ and $\mathrm{MnCr}_{2} \mathrm{O}_{4}$ are available from Chase et al (1975) and Jacob (Private Communication) respectively. In order to evaluate the stability of the oxides as a function of alloy composition in the $\mathrm{Cr}-\mathrm{Mn}-\mathrm{O}$ system, thermodynamic properties of the $\mathrm{Cr}-\mathrm{Mn}$ alloys have been used as reported by Eremenko et al (1968) and Jacob (1985) and those from the present isopiestic studies at $1323 \mathrm{~K}$. Thermodynamic properties of the $\mathrm{Cr}-\mathrm{Mn}$ system have been studied by Eremenko et al (1968) at $1023 \mathrm{~K}$ using a fused salt emf technique. Their results indicate positive deviations from Raoult's law. In the absence of any enthalpy data or data based on second law evaluation, the activity data as reported by Eremenko et al (1968) are used with reference to $\beta \mathrm{Mn}$ as standard state. The calculation assumes the excess free energy property of the $\mathrm{Cr}-\mathrm{Mn}$ system to be independent of temperature. Figure 3 depicts the variation of $-\log P_{\mathrm{O}_{2}}$ as a function of alloy composition at $1323 \mathrm{~K}$ which describes the stability range of various oxides in the $\mathrm{Cr}-\mathrm{Mn}-\mathrm{O}$ system. It also shows that the free energy change of the $\mathrm{MnO}$ phase coincides with that of $\mathrm{MnCr}_{2} \mathrm{O}_{4}$ at $X_{\mathrm{Mn}}=0.29$ at this temperature. The calculated values of the changeover composition using the data of Eremenko et al (1968) at 1173 and $1273 \mathrm{~K}$ are 0.26 and 0.25 respectively. More recently thermodynamic properties of the $\mathrm{Cr}-\mathrm{Mn}$ 


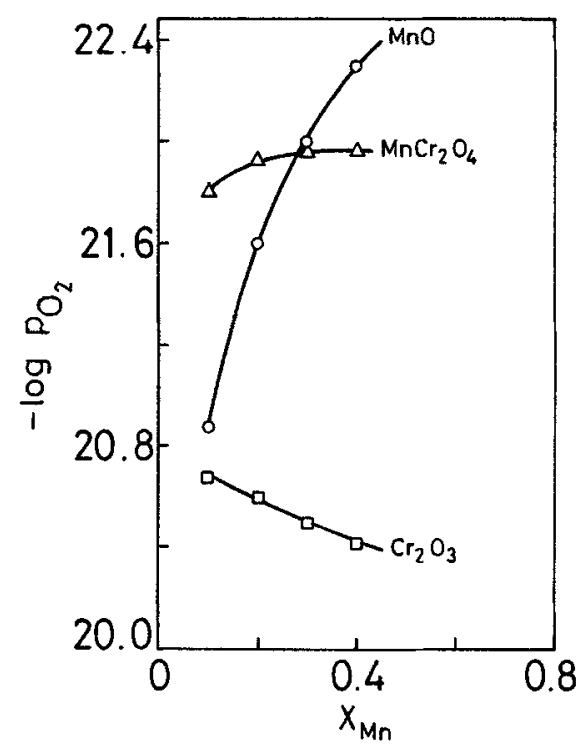

Figure 3. Logarithm of partial pressure of oxygen as a function of composition of the CrMn alloys using the extrapolated data of Eremenko et al (1968) at $1323 \mathrm{~K}$.

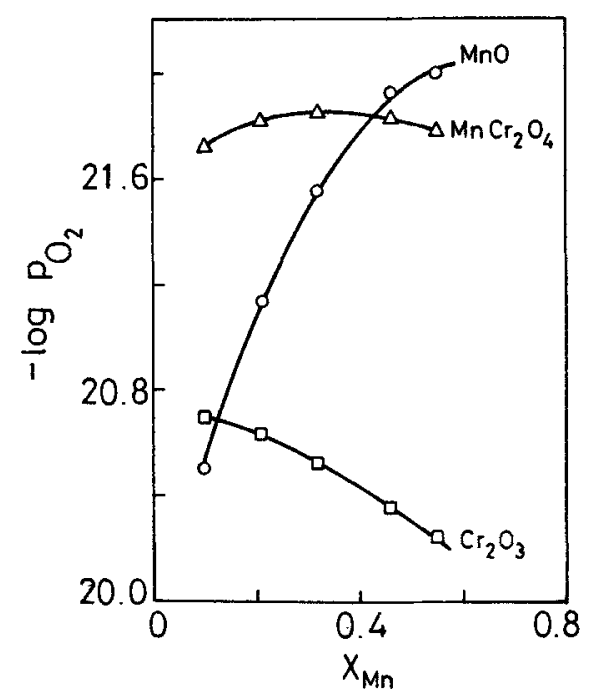

Figure 4. Logarithm of partial pressure of oxygen as a function of alloy composition based on the activity data determined by Jacob (1985) at $1323 \mathrm{~K}$.

system for $\mathrm{Cr}$ rich b.c.c. solid solution have been measured by Jacob (1985) using Knudsen effusion cell in the temperature range of 1200 to $1500 \mathrm{~K}$. The calculated relationship between the stabilities of the oxide phases and alloy composition at $1323 \mathrm{~K}$ based on his data is presented in figure 4 . The change-over composition at this temperature may be noted as $X_{\mathrm{Mn}}=0.43$. The corresponding calculated $X_{\mathrm{Mn}}$ values at 1173 and $1273 \mathrm{~K}$ are 0.41 and 0.38 respectively. 
The thermodynamic data of the Cr-Mn system based on the present investigation using isopiestic technique at $1323 \mathrm{~K}$ are expressed in terms of the activity coefficients of $\mathrm{Mn}$ and $\mathrm{Cr}$, in the range of $0<X_{\mathrm{Mn}}<0.65$ as

$$
\gamma_{\mathrm{Mn}}=2 \cdot 504-1.927 X_{\mathrm{Mn}} \text {. }
$$

and

$$
\text { In } \gamma_{\mathrm{Cr}_{\mathrm{r}}}=1 / 0 \cdot 2305\left[-0.7695 \operatorname{In}\left(1-X_{\mathrm{Mn}}\right)+\operatorname{In}\left(1-0.769 X_{\mathrm{Mn}}\right)\right] \text {. }
$$

Figure 5 depicts the variation of $-\log P_{\mathrm{O}_{2}}$ as a function of alloy composition using (4) and (5) in conjunction with (1), (2) and (3). The calculated change-over composition exists at $X_{\mathrm{Mn}}=0 \cdot 22$. The latter thermodynamically calculated value is in excellent agreement with $X_{\mathrm{Mn}}=0.252$ which is obtained from alloy-oxide equilibria followed by $x$-ray diffraction studies as reported in table 2. The change-over composition is considered to be important, as it delineates the phase boundaries of the $\mathrm{Cr}-\mathrm{Mn}-\mathrm{O}$ system. The existence of the three-phase equilibrium at this composition would make the coexistent partial pressure of oxygen imparted by the alloy $+\mathrm{MnO}$ to be equal to that by the $\mathrm{MnCr}_{2} \mathrm{O}_{4}$ + alloy phases at $1323 \mathrm{~K}$. Therefore using (1), (3), (4) and (5) at $X_{\mathrm{Mn}}=0.252$, the standard free energy of formation of $\mathrm{MnCr}_{2} \mathrm{O}_{4}$ has been assessed and found to be $-1133.86 \mathrm{~kJ}$ mole ${ }^{-1}$. This compares favourably with a value of $-1129.68 \mathrm{~kJ} \mathrm{~mole}^{-1}$ as given by Jacob (Private Communication) at $1323 \mathrm{~K}$.

The existence of the other three phase equilibria between $\mathrm{Cr}, \mathrm{MnCr}_{2} \mathrm{O}_{4}$ and $\mathrm{Cr}_{2} \mathrm{O}_{3}$ phases is indicated in tables 1 and 2 . Table 3 shows that for an alloy of almost pure $\mathrm{Cr}, X_{\mathrm{Mn}}=0.0001$ at $1323 \mathrm{~K}$, the $\mathrm{MnCr}_{2} \mathrm{O}_{4}$ and $\mathrm{Cr}_{2} \mathrm{O}_{3}$ phases coexist in equilibrium. In this dilute solution range, the activity coefficients of $\mathrm{Cr}$ and $\mathrm{Mn}$ in the alloy are used based on (4) and (5) such that $X_{\mathrm{Mn}}$ tends to unity, $\gamma_{\mathrm{Cr}}$ tends to 1.0 and $\gamma_{\mathrm{Mn}}$ approaches a value of 2.504 at $1323 \mathrm{~K}$. The $\mathrm{Cr}$-rich alloy, however, retains about 4 at $\% \mathrm{Mn}$ as reported in table 2 . This is considered to be due to lack of

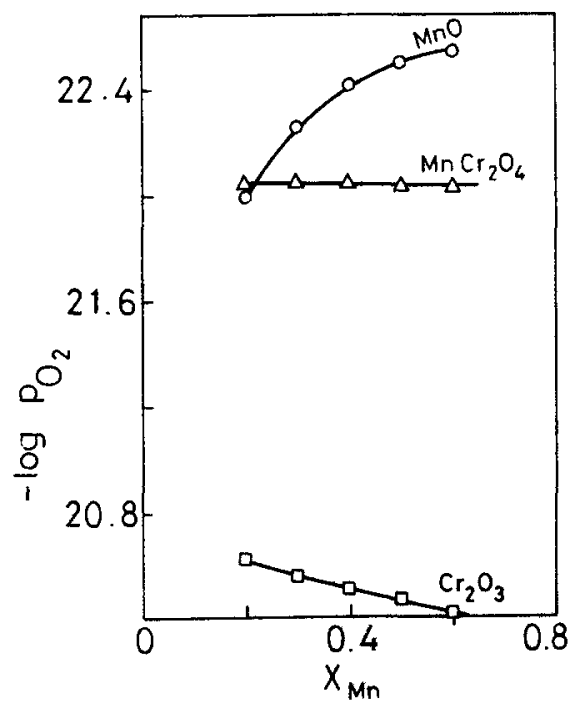

Figure 5. Variation of logarithm of partial pressure of oxygen with the composition of $\mathrm{Cr}$ $\mathrm{Mn}$ alloys based on the activity data determined by the isopiestic technique at $1323 \mathrm{~K}$. 
Table 3. Three phase equilibrium involving $\mathrm{Cr}, \mathrm{Cr}_{2} \mathrm{O}_{3}$ and $\mathrm{MnCr}_{2} \mathrm{O}_{4}$.

\begin{tabular}{lcc}
\hline$X_{\mathrm{Mn}}$ & $\mathrm{Po}_{2} \mathrm{MnCr}_{2} \mathrm{O}_{4}$, atm. & $\mathrm{Po}_{2}, \mathrm{Cr}_{2} \mathrm{O}_{3}$ atm. \\
\hline 0.001 & $9.52 \times 10^{-23}$ & $1.78 \times 10^{-21}$ \\
0.0001 & $3.00 \times 10^{-21}$ & $1.78 \times 10^{-31}$ \\
\hline
\end{tabular}

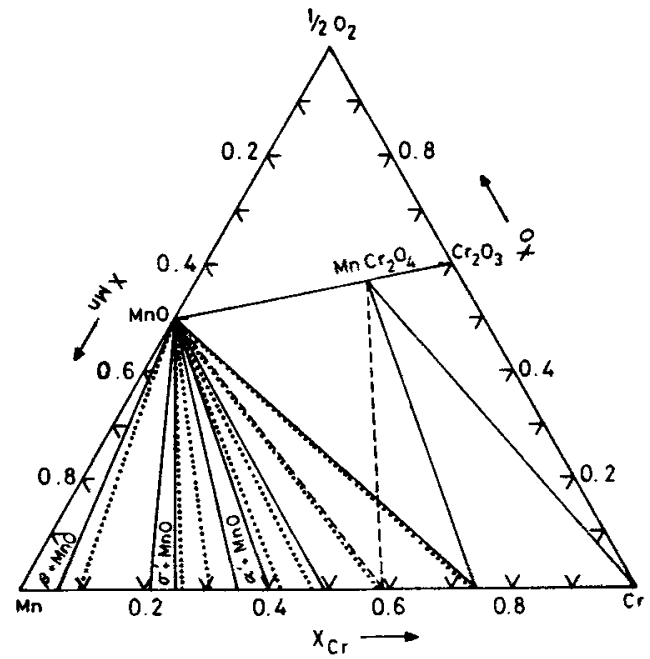

Figure 6. Isothermal section of the $\mathrm{Cr}-\mathrm{Mn}-\mathrm{O}$ system at $1173 \mathrm{~K}$. Comparison between the present data (. . . ) and those calculated based on the activity data of Eremenko et al (1968) $(--)$ and Jacob (1985) (-- )

thermodynamic equilibrium. It may be mentioned that the starting composition of the alloy was about 6 at $\% \mathrm{Mn}$ mixed with $\mathrm{Cr}_{2} \mathrm{O}_{3}$ which is expected to be extremely slow in giving up its $\mathrm{Mn}$ content to reach an equilibrium state containing alloy $+\mathrm{MnCr}_{2} \mathrm{O}_{4}$ phases.

The samples containing either $\mathrm{Cr}+\mathrm{MnCr}_{2} \mathrm{O}_{4}$ or $\mathrm{Cr}+\mathrm{MnO}$, as reported in table 1, reach equilibrium under the experimental conditions used in the alloy-oxide equilibrium studies. Consequently the existence of the equilibrium phases, $\mathrm{MnCr}_{2} \mathrm{O}_{4}$ and $\mathrm{Cr}_{2} \mathrm{O}_{3}$, has been detected by $\mathrm{x}$-ray analysis of the samples irrespective of their starting oxide phases. The tie line compositions of the $\mathrm{Cr}-\mathrm{Mn}$ alloys summarized in tables 1 and 2 are shown along with the thermodynamically calculated values in the isothermal sections of the $\mathrm{Cr}-\mathrm{Mn}-\mathrm{O}$ system. Figures 6, 7 and 8 denote the isothermal sections at 1173,1273 and $1323 \mathrm{~K}$, respectively.

The alloy-oxide equilibria and thermodynamic studies indicate the presence of $\mathrm{MnO}$ predominently in the $\mathrm{Mn}$-rich compositions and $\mathrm{MnCr}_{2} \mathrm{O}_{4}$ and $\mathrm{Cr}_{2} \mathrm{O}_{3}$ in the three-phase equilibrium with almost pure $\mathrm{Cr}$. The change-over of the chromate to $\mathrm{MnO}$ phase occurs when $X_{\mathrm{Mn}}=0.252$ at $1323 \mathrm{~K}$ which decides the other three phase equilibria in the $\mathrm{Cr}-\mathrm{Mn}-\mathrm{O}$ system. 


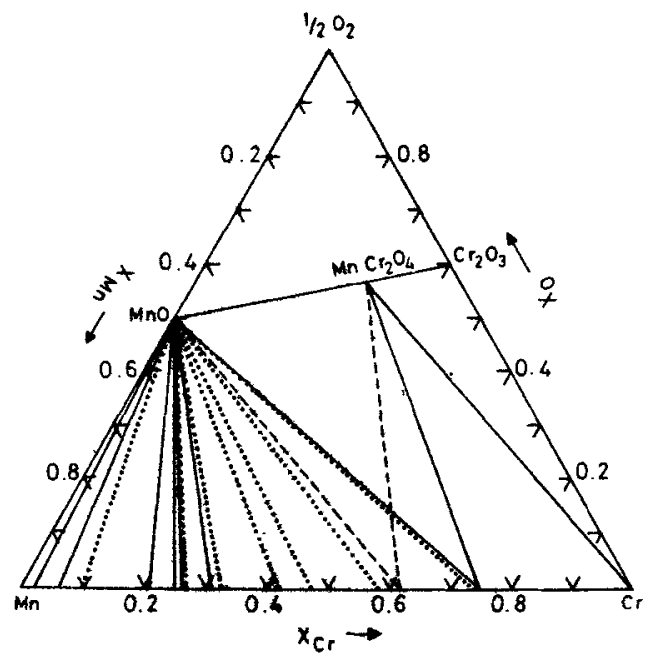

Figure 7. Isothermal section of the $\mathrm{Cr}-\mathrm{Mn}-\mathrm{O}$ system at $1273 \mathrm{~K}$. Comparison between the present data (...) and thermodynamically calculated values based on the data of Eremenko et al (1968) (_- ) and Jacob (1985) (-- ).

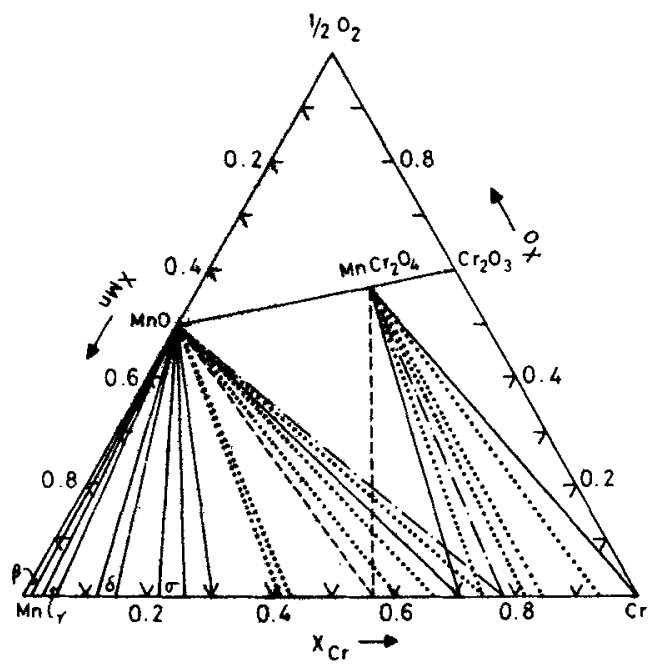

Figure 8. Isothermal section of the $\mathrm{Cr}-\mathrm{Mn}-\mathrm{O}$ system at $1323 \mathrm{~K}$. Comparison between the data of the present work (-.- isopiestic experiment; . . . alloy-oxide equilibrium) with values derived based on Eremenko et al (1968) (_- ) and Jacob (1985) (- - ).

\section{Acknowledgements}

The authors are grateful to the University Grants Commission for financial support.

\section{References}

Barin I and Knacke O 1973 Thermochemical properties of inorganic substances (Bẹrlin: Springer Verlag) Barin I, Knacke O and Kubaschewski O 1977 Thermochemical properties of inorganic substances (Berlin: Springer Verlag) Supplement 
Busch D H 1980 Inoryanic synthesis (New York: John Wiley) Vol. 20

Chase M W, Wrnutt J L, Prophet H and Mcdonald R A 1975 J. Phys. Chem. Ref. Data 492

Eremenko V M, Lukashenko G M and Sidorko V R 1968 Russ. J. Phys. Chem. 42343

Jacob K T 1985 Z. Metallkde 76415

Venkataraman M and Neuman J P 1986 Bull. Alloy Phase Diagrams 7457

Vogel A I 1969 Quantitative inorganic chemistry (London: ELBS \& Longman) 